\title{
Physical modelling of debris flow deposits in contiguous confluences
}

\author{
L.M. Stancanelli \& E. Foti \\ Department of Civil Engineering and Architecture \\ University of Catania, Catania, Italy.
}

\author{
S. Lanzoni \\ Department of Civil, Environmental and Architectural Engineering \\ University of Padua, Padua, Italy.
}

\begin{abstract}
Dam formation in river channel generated by single and multiple debris flow injections from affluent basins are investigated in through flume experiments. The aim of the research is to understand the morphodynamics that governs the dam formation. A set of 14 experiments considering both single and double debris flow injections have been carried out, investigating different configurations in terms of debris flow discharge, confluence angle and water discharge along the main channel. In all cases, the debris flow consisted of a mixture of gravel and water, that reproduces stony-debris flow conditions. Results from single confluence experiments are taken as reference for better understanding the interactions between the different deposits when considering adjacent debris flow injections. The collected data are used to test the critical indexes for dam formation probability proposed in literature.
\end{abstract}

\section{INTRODUCTION}

Debris flows often form in narrow steep valleys characterized by abundant loose materials, which become unstable under the action of water. In some cases, the propagation of these sediment-water mixtures on steep slopes and their debouching into a main stream may create sediment dams, with a consequent increase of the hazard related to upstream inundation due to breakwater effects, as well as possible downstream flooding resulting from dam failure (Clague et al. 1985). The dam formation is strongly influenced by the flow dynamics at the confluence. According to Dang et al. (2009) parameters which influence the dam formation are: discharge and velocity ratios between the tributary and the main stream, the bulk density of the debris flow, the confluence angle and degree of unevenness of grain size. Various critical indexes for assessing dam formation have been proposed in literature, based on empirical and experimental approaches. The former, being determined from observations on specific field sites, are strongly related to the environmental setting which they rely on. Small scale experiments have been typically used to analyze possible dam formation caused by the confluence in the main channel of a sediment-water mixture with a mixture with given characteristics (Dang et al. 2009, Cheng et al. 2007, Chen et al. 2004). In the present contribution we focus our attention on stony debris flow conditions an investigate whereby both single and multiple confluences lead to dam formation. The debris flow is generated by releasing a prescribed water discharge release over a saturated layer of gravel placed in the tributary flume. The aims is to provide information about the influence of confluence angle, debris flow discharge along the tributary and water discharge along the main river.

\section{EXPERIMENTAL INVESTIGATION}

\subsection{Experimental apparatus and procedure}

The laboratory investigations have been carried out at the Hydraulic Laboratory of the Department of Civil, Environmental and Architectural Engineering of the University of Padua (Italy). The experimental apparatus is designed in order to study debris flows propagation along two tributary channels, close to each other, which convey a gravel-water mixture into a river reach located downstream. The experimental facility consists of a main channel reach, hereafter denoted as channel A, $12 \mathrm{~m}$ long, $0.5 \mathrm{~m}$ wide, and with a depth of $0.70 \mathrm{~m}$; and two lateral channels, called respectively channel B (upstream) and channel $\mathrm{C}$ (downstream), that have a length of $3 \mathrm{~m}$, a width of $0.30 \mathrm{~m}$ and a depth of $0.30 \mathrm{~m}$. The lateral chan- 


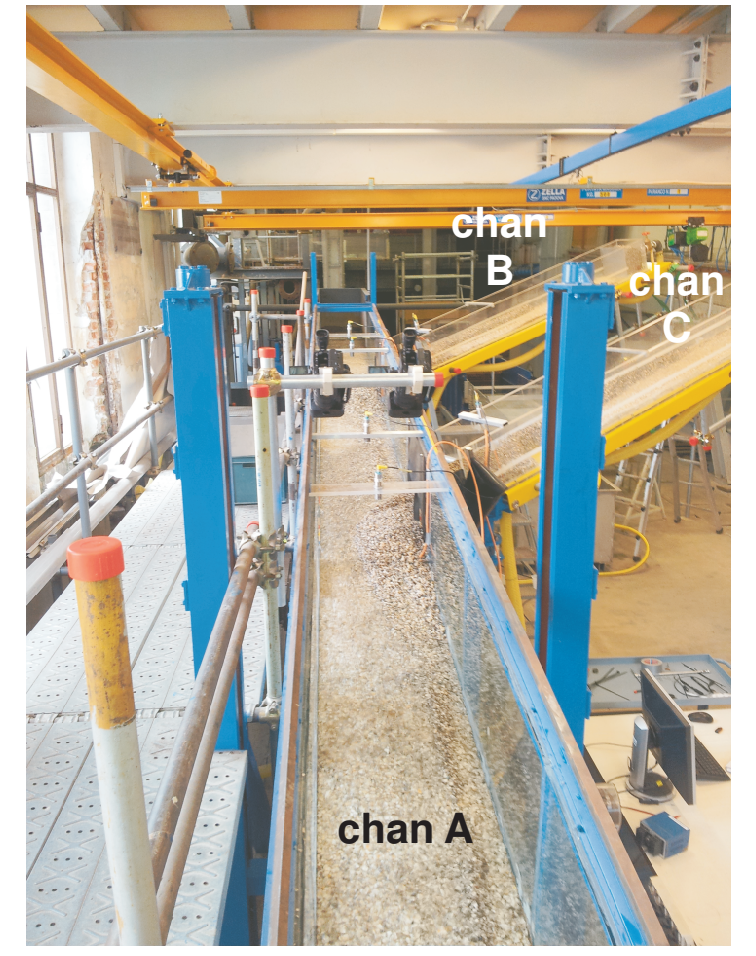

Figure 1: Downstream view of the main channel A, on the right side the channel B (upstream) and the channel C (downstream) form two different confluence.

nels are located on the left side of the main channel, at an interaxis of about $2.7 \mathrm{~m}$, and their connections consist of a particular joint system which allows to vary the channel slopes and the confluence angles (Figure 1). The sediment used to generate the debris flow was composed by nearly uniform gravel material, with grain sizes varying in the range from 2 to $5 \mathrm{~mm}$. As demonstrated in a previous experimental campaign (Stancanelli et al. 2015), by varying the tributary slope leads to debris flows which differ in sediment concentration and propagation velocity. Six acoustic level sensors (ensuring an error smaller than $0.001 \mathrm{~m}$ ) are installed along the various channels in order to monitor flow levels during the propagation and deposition phases. Video recordings from side view of the lateral channel and of the main channel are acquired by two cameras, with the capability of $100 \mathrm{fps}$.

The experimental procedure consists of a preliminary phase needed to fix the geometrical configuration of the experimental apparatus, selecting the slopes and the confluence angles of the lateral channels (set equal for both channels B and C), as well as the slope $\left(5^{\circ}\right)$ and the water discharge (in the range of $2-51 / \mathrm{s}$ ) within the main channel. Initially, the lateral flumes were filled with a $9 \mathrm{~cm}$ thick layer of gravel, that was then saturated by feeding a very low water discharge $(0.8 \mathrm{l} / \mathrm{s})$. A permeable sill was placed at the downstream end of both tributaries to prevent bed degradation during the saturation. The debris flow was subsequently triggered by a sudden release of water discharge (about $3.8 \mathrm{l} / \mathrm{s}$ ) within the tank placed at the head of the the considered flume. The debris flow generated within the upstream portion of the flume, formed a body that propagated downstream over the erodible bed, without causing significant erosion until the arrival of the tail, when the stored sediment was progressively washed out.

The debris flows thus generated were always of mature type, i.e, with the grains dispersed throughout the entire flow depth. After debris flows propagated in channels $\mathrm{B}$ and $\mathrm{C}$, the mobilized material was eventually deposited into the main receiving channel (A). The water flowing along it progressively shaped the deposited material and the experiment was interrupted when the geometry of the deposits did not change anymore. At the end of each experiment, the river bed was carefully surveyed and the geometries of the deposition fans observed in the various experimental configurations were compared together.

\subsection{Experimental conditions}

The set of experimental conditions here investigated are presented in Table 1, listing the relevant geometrical and hydraulic parameters, i.e., main channel water discharge $Q$, confluence angle $\alpha$, and debris flow discharge $Q_{d f}$ along the tributaries. Experiments from 1 to 11 have been performed with a single debris flow injection, generated along channel B; while in experiments from 12 to 14 two simultaneous debris flows have been generated simultaneously along the tributary channels B and C.

The debris flow discharge $Q_{d f}$ is essentially controlled by the tributary slope (Stancanelli et al. 2015). For a triggering water discharge of about $3.8 \mathrm{l} / \mathrm{s}$ and a tributary slope angle of $17^{\circ}$, the average debris flow depth and propagation velocity were about $0.06 \mathrm{~m}$ and $0.5 \mathrm{~m} / \mathrm{s}$, respectively; these values changed to $0.04 \mathrm{~m}$ and $0.6 \mathrm{~m} / \mathrm{s}$, in case of a $15^{\circ}$ tributary slope angle.

\section{EXPERIMENTAL EVIDENCES}

In order to assess the dynamics of dam formation at confluences, let us first analyze the case of a single confluence and later on that of two confluences. Figure 2 shows the comparison of longitudinal deposit profiles in the case of a single confluence, for experiments with the same confluence angle and water discharge along the main channel, but different debris flow discharge ( $7 \mathrm{l} / \mathrm{s}$ for test 7 and $9 \mathrm{l} / \mathrm{s}$ for test 8 ). It clearly appears that the higher deposit depth occurs for the larger debris flow discharge.

On the other hand, Figure 3 shows the top view of the deposit formed for given values of the debris flow discharge $(7 \mathrm{l} / \mathrm{s})$ and the water discharge along the main channel $(4.5 \mathrm{l} / \mathrm{s})$, but different confluence angles $\left(60^{\circ}\right.$, test 3 , and $90^{\circ}$, test 6$)$. The confluence angle turns out to influence the spatial distribution of the sediment deposit. In particular, for a perpendicular debris flow injection $\left(90^{\circ}\right)$ the deposit tends to distribute almost symmetrically upstream and downstream of the confluence, distributing more easily the 
Table 1: Summary of the relevant parameters characterizing the present tests. The various quantities are defined as follows: $Q$, water discharge along the main channel; $\alpha$, confluence angle between tributary and main channel; $Q_{d f}$, volumetric debris flow discharge delivered in the main channel by a tributary.

\begin{tabular}{c|c|cc|cc}
\hline & main channel (A) & \multicolumn{2}{|c|}{ upstream tributary (B) } & \multicolumn{2}{|c}{ downstream tributary (C) } \\
\hline test & $\begin{array}{c}Q \\
(l / s)\end{array}$ & $\begin{array}{c}\alpha \\
\left(^{\circ}\right.\end{array}$ & $\begin{array}{c}Q_{d f} \\
(l / s)\end{array}$ & $\begin{array}{c}\alpha \\
\left({ }^{\circ}\right)\end{array}$ & $(l / s)$ \\
\hline \hline 1 & 4.5 & 90 & 9 & - & - \\
2 & 4.5 & 60 & 9 & - & - \\
3 & 4.5 & 60 & 7 & - & - \\
4 & 4.5 & 85 & 7 & - & - \\
5 & 4.5 & 85 & 9 & - & - \\
6 & 4.5 & 90 & 7 & - & - \\
7 & 2.0 & 90 & 7 & - & - \\
8 & 2.0 & 90 & 9 & - & - \\
9 & 3.0 & 60 & 9 & - & - \\
10 & 3.0 & 60 & 9 & - & 9 \\
11 & 3.0 & 90 & 9 & - & 9 \\
12 & 5.0 & 50 & 9 & 50 & 60 \\
13 & 5.0 & 60 & 9 & 90 & 9 \\
14 & 5.0 & 90 & 9 & \multicolumn{4}{c}{} \\
\hline
\end{tabular}

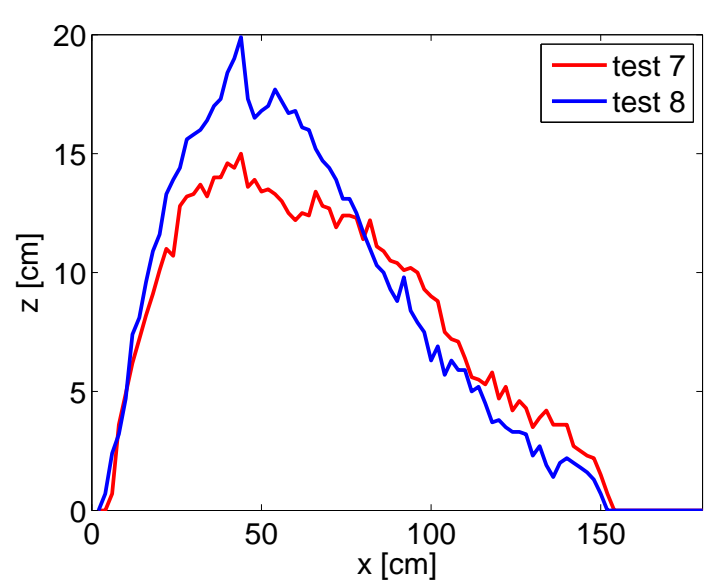

Figure 2: Comparison of longitudinal profile of the sediment deposit observed in the main channel (A) at the end of tests 7 and 8 , carried out with a single tributary with confluence angle $\left(60^{\circ}\right)$ and different debris flow discharges ( 7 1/s and 9 1/s).

sediment across the main channel section and, hence, causing a greater obstruction. Decreasing the confluence angle implies that the sediment deposit tends to elongate in downstream direction, favoring the wash out of sediment and resulting in a lower degree of obstruction of the main channel cross section (see Figure $3)$.

The parameter that seems to mainly influence the degree of obstruction within the main channel is the ratio between the debris flow discharge delivered by the tributary to the water discharge along the main channel. Figure 4 shows the top view of deposits surveyed at the end of experiments carried out with a debris flow discharge of $9 \mathrm{l} / \mathrm{s}$, a confluence angle of $90^{\circ}$, and different water discharges in the main channel, yielding decreasing values of the ratio $Q_{d f} / Q$ (4.5, test $8 ; 3.0$, test $11 ; 2.0$, test 1$)$. For $Q_{d f} / Q=4.5$ the main channel results totally obstructed and an impoundment forms upstream of the debris flow dam. A semi blockage of the main channel section is observed for $Q_{d f} / Q=3.0$, owing to the partial erosion
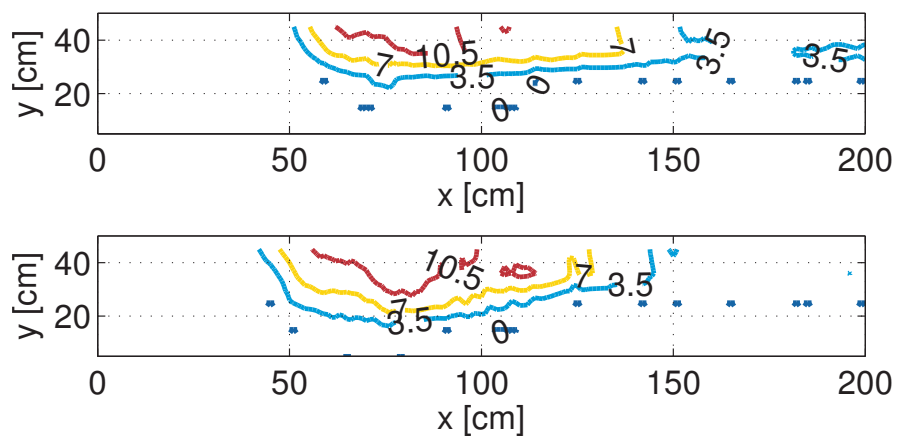

Figure 3: Top view of sediment deposits along the main channel observed for a single confluence, with a debris flow discharge of $7 \mathrm{l} / \mathrm{s}$, a main channel water discharge of $4.5 \mathrm{l} / \mathrm{s}$, and confluence angles of: $60^{\circ}$ (test 3 , upper panel, ); $90^{\circ}$ (test 6 , lower panel).

of the dam deposit near to the main channel bank opposite to the confluence. Finally, for $Q_{d f} / Q=2.0$ no dam forms.

The effects of nearby tributary channels is analyzed in Figure 5, comparing the results of two experiments
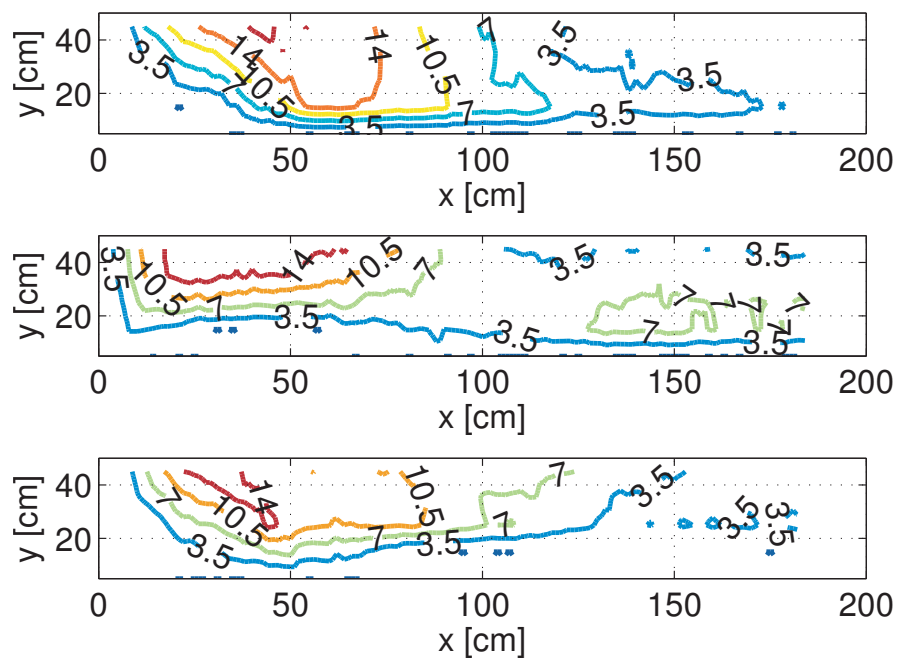

Figure 4: Top view of sediment deposits along the main channel observed for a single debris flow confluence $\left(Q_{d f}=9 \mathrm{l} / \mathrm{s}, \alpha=\right.$ $90^{\circ}$ ) at end of: test $8, Q=2 \mathrm{l} / \mathrm{s}$ (upper panel); test $11, Q=3 \mathrm{l} / \mathrm{s}$ (middle panel); test $1, Q=4.5 \mathrm{l} / \mathrm{s}$ (lower panel). 

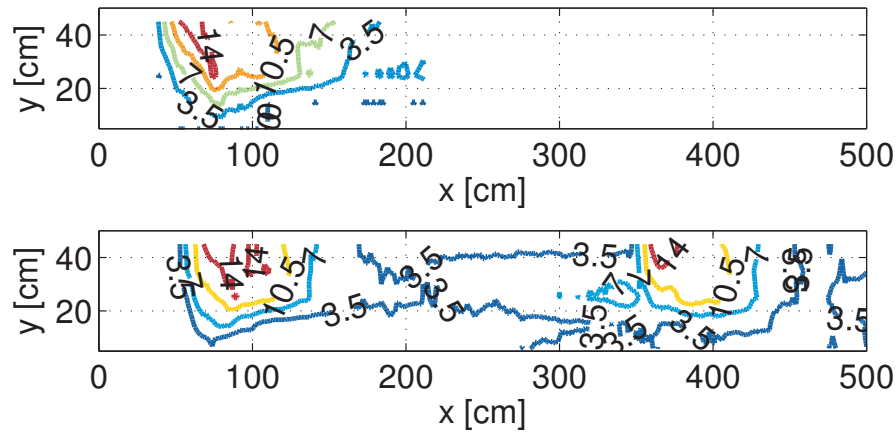

Figure 5: Top view of deposits along the main channel observed at the end of: test 1, single confluence (upper panel); test 14, double confluence (lower panel). The values of the relevant parameters are: $Q=4.5-5.01 / \mathrm{s} ; Q_{d f}=91 / \mathrm{s} ; \alpha=90^{\circ}$.

(1 and 14) carried out with the same $\alpha$ and similar values of $Q$ and $Q_{d f}$, but by considering either a single debris flow tributary or two simultaneous and adjacent debris flows. The contour lines observed in this latter case suggest that the sediment deposit formed nearby the upstream confluence is quite similar to that observed for a single confluence. This similarity is observed also when changing the confluence angle. The deposit formed at the downstream confluence has a shape totally different of that characterizing the single confluence case: the areal extension of the deposit and the overall height are much larger. Moreover, as expected owing to the simultaneous inception of the debris flows, a strong interference occurs between the two deposits (Stancanelli et al. 2015).

\section{CRITICAL INDEX FOR DAM PROBABILITY FORMATION}

The possibility of dam formation due to the sediment delivered by a debris flow in a receiving river is evaluated by applying critical indexes proposed by Dal Sasso et al. (2014) and Dang et al. (2009) on the basis of observations carried out for a single confluence. Although other empirical critical indexes are available in literature, we prefer to rely on these two indexes owing to their physical based character.

The first indicator is the Dimensionless MorphoInvasion Index $(D M I)$, proposed by Dal Sasso et al. (2014) to evaluate the probability of damming caused by a debris flow, and defined as the ratio of debris flow momentum to the main river momentum:

$D M I=\frac{2 \rho_{s} U_{s}^{2} V_{s}}{\rho g h^{2} B_{w} B_{t}}$

where $\rho_{s}$ and $\rho_{w}$ are the sediment and the water density, respectively, $V_{s}$ is the debris flow volume, $B_{t}$ is the tributary width, $h$ and $B_{w}$ are the water depth and the section width of the main channel A complete damming is expected to occur for $D M I>1$.

The second critical index was introduced by Dang et al. (2009) on the basis of flume experiments. It is based on the discharge ratio of debris flow discharge to river discharge $\left(R_{Q}=Q_{d f} / Q\right)$, the velocity ratio of debris flow velocity to river flow velocity
$\left(R_{U}=U_{d f} / U\right)$, the bulk density ratio between debris flow and river $\left(R_{\gamma}=\rho_{d f} / \rho\right)$, the sorting coefficient ( $\left.S_{c}=d_{75} / d_{25}\right)$ of the debris sediment, and the confluence angle, $\alpha$. The combination of these ratios yields the overall index:

$C I D F=R_{Q} R_{U} R_{\gamma} S_{c} \sin \alpha$

In the experiments used for deriving the index, Dang et al. (2009) observed a semi-blockage of the main river section for $C I D F<53.4$, with the water flowing at one side of the main channel section; for $57<C I D F<71.5$ a semi-blockage of the main river occurred, with the flow over-passing the deposited sediment; finally, a complete blockage of the river section was observed for $C I D F>83.4$.

In the case of a single debris flow confluence, the present data invariably lead to a DMI index in the range 238-924, thus predicting always a total blockage, despite this condition was observed only in a restricted number of experiments. This discrepancy is possibly associated with the high sensitiveness of the DMI index to the water flow depth $h$. Considering the ratio of debris flow depth to water depth in the main channel could improve the reliability of the index, but needs further investigations.

For the present experiments $S_{c} \sim 1$, owing to the almost uniform character of the adopted sediment. However, when a debris flow is triggered in laboratory by a prescribed water discharge flowing over a movable bed, the sediment-water mixture presents a velocity profile and a density that are strictly dependent on the sediment features. A change of sediment material results in a modification of the velocity profile, of the mixture density and, hence, of the debris flow rate (Lanzoni \& Tubino 1993). Therefore, in the present experiments, the influence of the grain size is implicitly accounted for through the debris flow discharge $Q_{d f}$, which influences the coefficient $R_{Q}$, as well as $R_{U}$ and $R_{\gamma}$.

Figure 6 shows the CIDF index evaluated on the basis of the present data and setting $S_{c}=1$ for those corresponding to the tests of Dang et al. (2009). The index appears to well describe the experimental evidence, namely the conditions of total and partial blockage for a single confluence. A possible extension of the CIDF index to the case of multiple and relatively close confluences can be obtained through the introduction in 2 of a multiplicative coefficient, $\varphi$, accounting for to the influence of the triggering scenario characterizing the debris flows in the tributary flumes (Stancanelli et al. 2014):

$\varphi=\varphi\left(1+\frac{B_{w}}{L_{c}}\right)$

where $L_{c}$ is the distance between two adjacent confluences, The coefficient $\varphi_{s}$ is related to the triggering scenario, namely: I) debris flows generated first on the upstream tributary and then on the downstream 


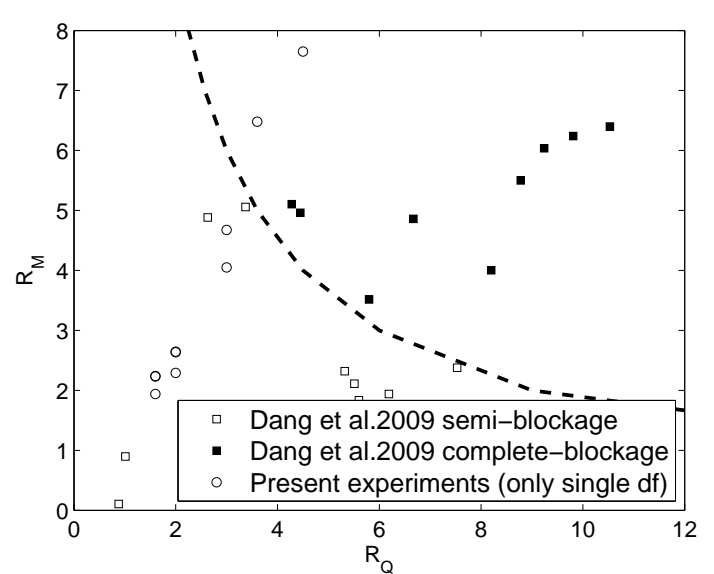

Figure 6: Evaluation of damming formation applying the CIDF Critical index. The results provided by the present data for a single confluence are compared with those of Dang et al. (2009).

tributary, $\varphi=0.6$; II) debris flows generated first on the downstream tributary and then on the upstream tributary, $\varphi=0.8$; III) debris flows occurring simultaneously in the two tributaries, $\varphi=1$.

As shown in Figure 5, for a fixed ratio $B_{w} / L_{c}=$ 0.5 , the shape of the upstream deposit does not change significantly for debris flows occurring simultaneously (triggering condition characterized by the higher $\varphi$ coefficient), while the downstream deposit increases in size. Of course, the mutual interaction between two confluences progressively decreases as their distance increases. Smaller values of $B_{w} / L_{c}$ (say $\leq 0.1$ ) will likely imply a negligible interaction between the two deposits, and the damming can be evaluated as a resulting from a single debris flow confluence.

\section{CONCLUSIONS}

The height of the dam that can form in a mountain channel consequently to the lateral injection of sediment delivered by a debris flow clearly increase with the sediment-water mixture discharge. Changes in the confluence angle cause a different planimetric displacement of the sediment deposit along the receiving channel. The released mass of sediment is shaped, through erosion, by the water flowing in the channel. The degree of obstruction strongly depends on the ratio of debris flow discharge to water discharge in the main channel. The presence of contiguous debris flow confluences appear do not alter significantly (at least for the range of investigated parameters) the morphology of the upstream deposit. The data collected in the case of a single confluence indicate that the DIM critical index Dal Sasso et al. (2014) provides a too conservative estimate of damming likelihood, possibly owing to the too large weight given by the index to the water depth within the main channel. Application of CIDF critical index Dang et al. (2009) results in a fairly and accurate predictability of dam formation for a single debris flow confluence. The CIDF index can be extended to two contiguous confluences by intro- ducing a multiplicative coefficient accounting for the relative distance between the confluences themselves and the difference in time of debris flow occurrences.

Acknowlwdgments This work has been partly funded by the Italian Ministry of Education, Universities and Research MIUR through the Research projects of significant national interest - PRIN 2012 - project Project "Hydro-morphodynamics modelling of coastal processes for engineering purposes"'(cod. 21040530/2013/725021028) and through the EU funded project HYDRALAB PLUS (proposal number 654110).

\section{REFERENCES}

Chen, S., S. Peng, \& H. Capart (2004). Morphology of alluvial fans formed by hyperconcentrated tributaries. In Proceedings of the 2nd International Conference on Fluvial Hydraulics, Napoli, Italy, pp. 1095-1102.

Cheng, Z., C. Dang, L. Jingjing, \& G. Yiwen (2007). Experiments of debris flow damming in southeast tibet. Earth Science Frontiers 14(6), 181-185.

Clague, J. J., S. Evans, \& I. G. Blown (1985). A debris flow triggered by the breaching of a moraine-dammed lake, klattasine creek, british columbia. Canadian Journal of Earth Sciences 22(10), 1492-1502.

Dal Sasso, S., A. Sole, S. Pascale, F. Sdao, A. Bateman Pinzón, \& V. Medina (2014). Assessment methodology for the prediction of landslide dam hazard. Natural Hazards and Earth System Science 14(3), 557-567.

Dang, C., P. Cui, \& Z.-1. Cheng (2009). The formation and failure of debris flow-dams, background, key factors and model tests: case studies from china. Environmental geology 57(8), 1901-1910.

Lanzoni, S. \& M. Tubino (1993). Rheology of debris flows: experimental observations and modelling problems. Excerpta of the Italian Contributions to the Field of Hydraulic Engineering 7, 201-236.

Stancanelli, L., S. Lanzoni, \& E. Foti (2015). Propagation and deposition of stony debris flows at channel confluences. Water Resources Research 51(7), 5100-5116.

Stancanelli, L. M., S. Lanzoni, \& E. Foti (2014). Mutual interference of two debris flow deposits delivered in a downstream river reach. Journal of Mountain Science 11(6), 1385-1395. 